\title{
Class teacher trainees' conceptions of their own learning, mentoring and tutoring in
} teaching

\author{
Marjaana Soininen \\ Tuula Merisuo-Storm \\ University of Turku, Finland, Department of Teacher Education, Rauma Unit \\ marjasoi@utu.fi \\ tuumer@utu.fi
}

DOI:10.5901/mjss.2014.v5n22p120

\begin{abstract}
Class teacher education in Finland differs in several aspects from the training the future teachers get in other countries. First, the training takes place at universities. Second, it takes five years to finish the studies. Third, along the teacher's certificate the students get the master's degree. Fourth, the teaching training takes place mainly in the training schools connected to the universities. Fifth, the students entering the Finnish class teacher education are older than in many other countries. The teaching practice at the Department of Teacher Education in Rauma Unit is divided into four practice periods: basic teaching practice 1, basic teaching practice 2, thematic/research teaching practice, and subject specific teaching practice. The training is altogether 26 study credits out of 300 ECTS. The teaching practice is supervised by tutors who are teachers within the department of teacher education, in Finland they are usually lecturers of different subjects, and by mentors who are teachers working at the schools where student teachers are trained. This article focuses on how student teachers reflect their learning, and how they evaluate practical training and the role of a tutor and a mentor. The research instrument is an electronic questionnaire, which the trainees answered after each four training periods. The number of respondents was 239. The type of research is qualitative. The results of the study show that during the first training period some of the trainees started to think about teaching as a profession. In addition, they started to understand the role of a mentor. However, they claimed that some mentors had not found out the main idea of mentoring. According to the students, several mentors clung to their own ideas and did not enable the reflective thinking of trainees. During the second training period trainees started to see a teacher as a transformer of knowledge not just a deliverer of knowledge. In this practice, a tutor as well as a mentor had an important role in advising a trainee to take a more independent role. The third teaching practice included teaching of several different school subjects. Consequently, the roles of a mentor and a tutor were sometimes confusing for the trainee. The mentor was supposed to give theoretical advice and the latter practical advice. During the fourth practice student teachers could understand the children of different ages better as well as reflect their own behavior in the classroom more skillfully than in the first practice.
\end{abstract}

Keywords: Teaching Training, Mentoring, Tutoring

\section{Introduction}

While reading literature connected to this topic one can very easily notice that the teacher education, especially for those aiming to be class teachers, varies in different countries (e.g. the Netherlands, the UK, the US, Greece) as well as the teaching practice. According to Zanting, Verloop, and Vermunt (2001) teacher preparation has typically been situated in schools rather than in higher education institutions. Whereas in Finland teacher education has been a part of universities since 1974, which year was a turning point in the Finnish teacher preparation. The teacher education became more academic. Since then, there have been various changes in the class teacher education.

The Finnish class teacher education has been built according to the Bologna Process to consist of two academic degrees; a lower academic degree of 180 credits completed in three years and giving a student the Bachelor's degree (BA), and a higher academic degree of 120 credits completed in two years ending at the Master's degree (MA). To get the certificate for teaching a student has to attain MA. (Jakku-Sihvonen \& Niemi 2006.)

By the time the students enter a university, they have been at school 12 to 13 years, at least, and they have observed the work of their teachers and usually have formed some expectations about the role of a teacher. They might have formed 
very deeply grounded beliefs and attitudes about teaching (Karavas \& Drossou 2009). In Finland, it is very hard to enter the teacher education. Consequently, most of the students have attended several times to the entrance exams, and some of them have experience about teaching that they have got by serving either as a school aid or a substitute teacher. This setting gives a challenge to the teacher education.

\section{Definitions of the terms}

Class teachers are teachers in comprehensive schools who are teaching mainly grades 1 to 6 , but they are also qualified to teach grades 7 to 9 in certain subjects; the age of the pupils varying from 7 to 15 .

Concepts such as a mentor and a tutor get different meanings in different contexts (Krull 2005). The term 'mentoring' is frequently used. It is also a term that has been used for a long time (Le Cornu 2005) in many connections and among different occupations. In many countries, the term 'mentoring' has been connected also to teaching. Lai (2005/2006) made a review of the mentoring literature and found that "there is no agreed conceptualization of mentoring among teacher educators and educational researchers" (p. 107). A similar conclusion can be read in the article of Levine (2011). Usually, mentoring includes the interaction between a new professional and a veteran professional (who has been chosen as a mentor). For this reason it is essential to determine how these concepts are understood in this study, and which concepts are used in parallel meaning.

Mentors are teachers working at the school where student teachers are trained. Since the system of the teacher training in Finland compared with other countries is different, class teachers (in Finnish luokanlehtorit) of the Finnish training schools (in Finnish normaalikoulut) are called mentors. They can also be teachers at the local schools, who are assigned for the training of the university, as the custom is in many other countries (Zanting et al. 2001; Taylor 2008). Tutors are lecturers, who supervise prospective teachers within a department of teacher education. In the recent literature, one can find a concept the university tutor (see Taylor 2008). In Finland, they are usually lecturers of different subjects (mother tongue, mathematics, history etc.), who are called in Finnish didaktikot (the concept stems from the word didactic). They could also be named as university teacher educators (Taylor 2008) or university supervisors (Zanting et al. 2001). Teacher trainees are student teachers, who practice teaching at the university training school (also called lab schools) and are supervised by mentors and tutors. They are also called in this article as prospective teachers.

The qualification requirements for all teachers (mentors) working at a Finnish training school may also differ from the ones, who are acting as mentors in other countries. The Finnish teachers have to have at least a Master's degree including so called pedagogical studies (60 ECTS credits). In addition, before appointed to this position they have to have a minimum of two years of full-time teaching experience, they have to obtain good teaching skills that they prove by giving a demonstration lesson when applying for a vacancy. Furthermore, the teachers of teacher training schools have to be experiment and research oriented, since one of the aims in teaching practice is to create an innovative and analytical attitude among the prospective teachers. (Jakku-Sihvonen \& Niemi 2006.) The qualification requirements for tutors are minimum of a Master's degree for university teachers and a Doctor's degree for university lecturers.

\section{Teaching practice in Finland}

Teaching practice is an essential part of a teacher education, as are the roles of a mentor and a tutor in creating a harmonious and productive working environment. A mentor and a tutor must therefore encourage open and clear communication, encourage everyone to contribute to discussion, make everyone feel valued, and ensure that the training has clear objectives and they are achieved. A good mentor and a tutor who encourages trainees to be creative in thinking must also be able to appreciate their answers and solutions. This means that the interaction between a mentor or a tutor and a trainee should be positive, open and encouraging. The atmosphere in tuition should generate critical thinking, but also openness. A prospective teacher should feel that his or her thoughts and perspectives are being appreciated and valued. (Soininen 2004.)

The teaching practice at the Department of Teacher Education, Rauma Unit, in the University of Turku, Finland, is constructed according to two stage structure. During BA studies the students are obliged to take part in two training periods, which are a part of intermediate studies and called the Basic Teaching Practice 1 (BTP 1; 5 credits) and BTP 2 (7 credits). The objectives for BPT 1 are: to support trainees' development into professional teachers by giving them an opportunity to become familiar with the tasks a teacher is responsible for, by allowing them to practice their communication and interaction skills in classrooms, and by applying theoretical studies in practice. Another objective is that they learn teaching and 
learning methods; teaching, planning, practice, observation, and teaching assistance and participation in general class work. The objectives for BTP 2 are: to enhance trainees' knowledge in planning, teaching and assessment, and to strengthen teaching and learning methods; teaching, observation, planning, teaching assistance, tutoring other school activities. These two teaching practice periods are done in pairs in certain school subjects. After BA degree a student can continue to advanced studies that include the Thematic Teaching Practice (TTP; 7 credits) and the Subject Specific Teaching Practice (SSTP; 7 credits). The objectives for TTP are in short: to develop the skills required to enhance personal teaching style, and to learn to analyze and evaluate students' as well as one's own work, and to get acquainted with home and school partnership. The objectives for SSTP are in brief: to plan, to carry out, and evaluate larger teaching sessions in connection with curricula, and to practice in taking more individual responsibility of teaching. These two training periods are individual training periods, which means that a trainee is responsible for all that takes place at school during one week. The practice is more compact than BTP 1 and BTP 2. One credit is approximately 27 hours of workload. Practice periods are not graded with numbers, only pass - fail.

\section{Theoretical frameworks}

The literature provides several models of mentoring, but in this article only three of them are specified. The first one is called the apprenticeship model or the master-apprentice model, where mentors usually have the role of a model. In this model teacher trainees observe experienced teachers in their work and form ideas about the process of teaching. The second model is the competency model or the clinical supervision model, in which novice teachers learn to teach by practicing different teaching strategies and techniques under the observation of mentors as well as tutors. The third model is called the reflective model. In it, the students are required to evaluate critically different ways of teaching in order to extend their teaching repertoire and develop their deeper understanding of the process of teaching. (Franke \& Dahlgren, 1996; Zanting, Verloop \& Vermunt, 2001). The change from the apprenticeship model to the reflective model of teaching should be seen during the teaching practice periods. Lai (2005/2006) sees mentoring as a process of skill acquisition, which is connected with technical activities: 'the mentor passing on a "bag of tricks" to the mentee' (see also Jakku-Sihvonen \& Niemi, 2006) or as a process of enculturation to the school world. Mentoring seen as a process of skill acquisition is a narrower definition than mentoring as an enculturation process.

The teacher trainees themselves should have a cognitive psychological view on learning and teaching. This means that learners (here student teachers) should be active, constructive and self-directed, and they should construct their personal knowledge and understanding, their own philosophy to teach. What is a role of a mentor in this process? Zanting et al. (2001) have mentioned several roles they have found from the literature. They point out that this role can be much more than a role of being a model or an instructor; it can be an information source for tips and advice during training. A mentor can be called a challenger, a coach, a supporter or an evaluator. Mentors use much more time with the trainees than university supervisors (tutors). Zanting, Verloop and Vermunt (2003) argue that mentors' practical knowledge is crucial in teaching practice. The literature shows that student teachers are focusing more on their own teaching than on the mentor's teaching skills. Mentors should provide possibilities for trainees to explore mentor's knowledge and beliefs about teaching (see also Crasborn, Hennissen, Brouwer, Korthagen \& Bergen 2011).

It is obvious that the practical studies are one of the most important parts of the teacher education, which according to Jyrhämä (2006) plays a key role in how teacher trainees see their profession in the future. All teacher education programmes include so called theoretical studies and teaching practice. The most often asked question is how to combine these two elements most efficiently? Students do not seem to understand the connection between theory and practice or the ability to apply theory to practice develops slowly. In this, the role of a university supervisor (tutor) comes up. Usually, tutors represent one of the school subjects (e.g. mathematics, history, mother tongue) and they teach students the theoretical structures and teaching strategies of their subjects. Also other studies, such as educational psychology, social psychology, educational philosophy, special education, should be connected to practice. Mentors and tutors should have a common agreement about how and what to teach to student teachers. It is important because a tutor supervises a trainee and observes his or her teaching only couple of hours during the training period, but a mentor spends the whole training period with a prospective teacher. Everyone should be able to adjust his or her attitudes, values, and beliefs, which he or she should adjust to meet the others' attitudes, values and beliefs.

The physical learning environment, the context, which is a combination of cognitive and emotional structures where mentoring and tutoring take place, should be safe, harmonious and pleasant. There should be a good understanding between the three parties shown in Figure 1. 


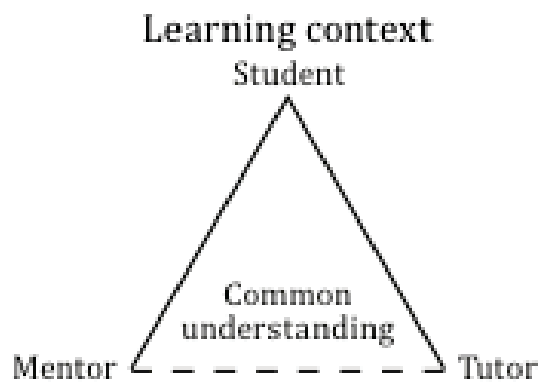

Fig.1 The connection between the three parties during a teaching practice

As shown in Figure 1, there are always three actors involved more or less actively in teaching practice. The learning context is either the university and its teacher education curriculum or the teaching training school and its curriculum. Both curricula should be active for each of the three parties. A common model is that during his or her academic studies, the trainee is aware of the tutor's (a subject didactics lecturer) curriculum, and during the teaching practice he or she is aware of the mentor's (a class teacher) curriculum. The important fact is that also mentors and tutors should be familiar with these two curricula. Figure 1 also implicates that tutors, mentors and student teachers should work in triads (see also Taylor 2008). This means 'that student teachers' work is done in complex settings where an array of people with varied histories, understandings, beliefs, and perspectives on instruction and curriculum interact" (Valencia, Martin, Place \& Grossman 2009, 304). Several studies (e.g. Bullough \& Draper 2004; Veal \& Rikard 1998) also show that triads are hierarchical; in most cases university supervisors are regarded as those being on the top. However, in Figure 1 a tutor (university supervisor) and a mentor (class teacher) are on the parallel level, because their roles can be considered equal in the process of teaching practice in certain aspects.

Student teachers learn from experts who are their mentors and tutors. For this reason, one should be aware that always when having a conversation either between a mentor (tutor) and a trainee, or between these three parties, attention should be paid to the quality of the professional dialogue (Harrison, Lawson \& Wortley 2005). One should teach by one's own example of how to bring critical reflection on practice. For this reason, among other things, it is important for mentors to be methodical not only for tutors. Harrison et al. (2005) found out in their intervention that there is a proportion of prospective teachers" whose capacity and/or willingness to reflect become a significant feature in their professional development" ( $p$. 288). Their working definition for critical reflection on practice is that it is about the exploration of 'why' and 'how' something is (or might be) done. It is important to notice also that the act of describing something (in this study one's own learning) is an individual interpretation, where one stresses some particular features and may leave some very important ones outside.

\section{Method}

\section{Aims and research questions}

The aims of the study are: first, to see how student teachers reflect their own learning during different teaching practice periods, second, to find out what the trainees' perceptions and views of mentoring and tutoring were after each teaching practiced period, and third, to reflect the teacher trainees' comments on the aims of the practice periods in order to change the practice towards more open and sensitive training. The specific research questions are: What the trainees have learned during the teaching practice periods? Does a trainee or a mentee see her or his mentor as an authoritarian instructor or as a supportive facilitator? Does the role of a mentor change during the four training periods?

\section{Research instrument and data}

After every training period, the trainees have to fill an electronic questionnaire including four questions: 1) What have you learned during your practice period? 2) What was good in the practice period? 3) What would you change within the practice period? 4) Do you have something else to comment? In this article, the answers are used as a database and the 
intention is not to answer the questions mentioned above but to see the texts as a whole. The main intention is to see how the roles of a mentor and a tutor raise from the students' answers during the different training periods. The second intention is to give the reader an example of how a supervising process is constructed in the Finnish teaching practice.

The first training period (BTP 1) takes place during the spring semester of the second year of the studies. The second training (BTP 2) is during the fall semester of the third year of the studies. The third training (TTP) takes place during the fall semester of the first year of the Master's degree. The last training period (SSTP) is at the beginning of the spring semester of the second year of MA. The database of this article includes the answers of the students who filled the questionnaire after their first training period, BTP1 $(n=68)$, after their second training period, BTP $2(n=52)$, after their third training period, TTP $(n=65)$, and after their last training period, SSTP $(n=54)$. The data was given anonymously; consequently the gender of the tutors, the mentors or the student teachers is not available.

Though the data is large in numbers quantitative methods are not used when analyzing it, instead the qualitative answers of the student teachers' beliefs of their own learning were read using case study methodology and the grounded theory approach. The data analysis was guided by the first question mentioned above. At the first stage, the data was read several times to get the overall view of the answers. The second stage was to color-code certain words and sentences to find out, which were the main themes that could be raised from the text connected to every four practicing period. The numbers after every example show on the one hand to which training period $(I-I V)$ it is connected, and the other hand the number of the answerer $(1-68)$. Since the answers were written in Finnish, the examples were translated into English as identical in meaning as possible, and in the way the trainees had written them.

\section{Results}

The answers varied considerably in content; there were answers from two words to 212 words; from no more than some concepts to specific concepts; from surface learning to deep learning. This implicates that there were huge differences among the students' conceptions about their learning. Some of them had really concentrated in reflecting, what he or she had learned, but from some answers could immediately be seen that the respondent had not paid any attention to the question.

During the first training period (BTP 1) the trainees learned technical, concrete and practical things. In addition, they had already learned to reflect their own learning. The role of a mentor was also important during this practice period.

"One has to put effort on lesson planning and pay attention to all possible things. (Also those that you cannot even memorize.) At first we did the lesson plans much too inaccurate. Fortunately, our mentor told us right away that we need to include all possible, also pupils' probable reactions / comments related to the topic that is taught. The concept "lesson" got a new meaning. We noticed that 45-minute-long lesson is often after all too short. With good planning one can use it most effectively." (I/14).

"I learned all kinds of things that I don't bother to begin to list. Most important were practical things that make teaching easier. I got guidance in every (4) subject, and it helped a lot . From the teacher (mentor) I got plenty of new ideas, for example, of teaching religion. I learned to act with the second graders, before this I have mainly worked with 5-6 graders." $(1 / 31)$

Next quotations show the problem that was demonstrated in Figure 1. It seems that the mentor and the tutor do not cooperate, and the trainee uses this situation; "learns to please them". Some of the mentors seem to keep tightly to their own ideas and do not enable student teachers' reflective thinking. The trainees learn very easily to please the mentors and the tutors, and they act as they are wanted to. This leaves no space for trainees to act according to their own strategies or use new teaching methods.

"I learned to please the tutor and the mentor. The problem in this training period is that there exists no co-operation, and it is bad for a trainee. We have to make the plans so that the both shall sign the paper, and they won't do it unless the plan is exactly how they want it to be. Of course, there are exceptions, but some of the teachers (mentors) are such who do not accept one's own new ideas to their classes. I imagine that during the first training period the main goal is to learn, for instance, by doing mistakes. It is better that I will see through my own performance the problems than that the mentor says that it is not possible to do it like that "because we have this kind of habit in this classroom" or "because I have been as a teacher already for so long that I know that it does not work". Maybe the mentor knows what he or she is talking about, but it does not help a trainee." (1/68) 
"Didactics lecturers (tutors) often stress that trainees should try different things. In practice class teachers (mentors) have quite often a clear "vision" about teaching. As a trainee I feel sometimes that I am between 'the tree and the bark', on the one hand I am encouraged to try and on the other hand I should do it in a way it has always been done. It is often very frustrating! To this I need coherence". (I/20)

These examples reveal that cooperation between the tutors and the mentors who are working in the same triad does not always function. There is a great need for tutors and mentors to enhance their own supervising. The result is similar to the one Veal and Rikard (1998) reported.

The second basic training (BTP 2) was very similar to the first one, but now the four subjects that the trainees practiced in pairs were different. However, the training took place in the same classes in most of the cases under the same mentor, although the tutors changed due to the different school subjects. While students' reflections were very similar to the first ones there was one significant change: now a child or children were mentioned in most of the answers.

"I learned to pay more attention to pupils' own experiences as a base of my teaching. Our mentor supervised us (like at the first training) giving advice, how to get children to become active knowledge processors. I also learned to give more space to conversational teaching style; a teacher does not need to explain everything, so pupils' own thoughts became now more out. Thank you for the mentor, who is really an expert!" (II/9)

"The best were the new challenges and possibilities in teaching. The other good thing was the feedback discussions with the class teacher (mentor). She (he) gave constructive feedback about my teaching and gave good hints to different situations. She (he) made me also to think my own teaching and (made me) to reflect, what I myself thought about it, and what went well and what went wrong in my teaching. The teaching environments as well as the teaching facilities were good." (II/15)

"I learned a lot, thanks to my XX supervisor. I got new views to my teaching, like how to use (different) concepts in teaching. $X X$ gave a lot of good advices before, during and after the lessons. I tried to learn from XX as much as I could in order to get new views to my teaching for my future teaching career. Methods were new to me, but I noticed that there is a lot of good in them. I will use them also later. In music teaching I got support that I also needed. I found out how a music lesson has to be constructed and from what strings to pull to get children to become stimulated. Thanks to XX!" (II/21)

The student teachers also learned how to work with pupils of different ages. Maybe during the first training period there was so much new to be learned that the children's age did not show up in the same meaning as during this second training.

"I learned to work with the first graders ( in Finland they are approx. 7 years old), I learned to manage the class. I also learned more about the subjects. I learned to be more persistent with the other trainees in the same class and to take up feedback." (II/32)

When reading the students' comments after the two training periods, it was found that the mentor's role was similar to the one in the competency model explained before. The students do not any more regard them as role models in a way they did during the first training period. It is also worth mentioning that now the students' comments included only a few mentions about the tutors.

The third teaching practice (TTP) differed from the two previous ones. Now student teachers taught in their practice class all the lessons during a whole school week. Their practice covered not only teaching different subjects, but also all the other work a class teacher has to do during a week, such as keeping an eye on pupils during the lunch hour and the breaks between lessons, consulting with parents and so on.

"I learned a lot for example, when for the first time my lesson was video recorded in the studio class. It was really instructive to see the video! In top of all I got acquainted with a pupil with learning disabilities. That was the first time I was in an elementary class, and in fact it was good to see how much time is needed there." (III/21)

"I was also satisfied that I got feedback of every lesson I taught. Good was also that the teacher (mentor) did not interrupt my teaching but gave the feedback after the lesson. This strengthened my authority and affected the controlling of the class." (III/24)

The quotations above show that also video recordings of the lessons were found to be very educative. Watching the recordings with mentors and tutors is an excellent way to reflect one's action in the classroom. In didactic seminars, student teachers can share their opinions and ideas about teaching practice. These seminars were found very educative and important. 
The fourth and last practice period (SSTP) took place at the beginning of the spring semester. The students' comments showed, among other things, that they had learned how to assess pupils in various ways. Since they had already some knowledge about different school subjects, which are taught at the primary level, they were able to get deeper to a subject and use new methods.

"I learned a lot of new things. Actually, I can say that during this training period I got out most for my future career. This was mainly due to my mentor who was supportive, encouraging and gave constructive feedback. I learned a lot since I was for the first time at this grade level. Teaching one subject ten hours makes you learn. I am not good at the subject I taught, so I had to work hard. (IV/2)

"This was the best practice of all! The class teacher, pupils and the environment supported my own teacher hood. I learned that having a good supervisor has a great meaning. I got support, help and possibility to carry out my own ideas. From several other trainees I heard that some class teachers who are so fixed to their own ideas do not allow student teachers to try anything new." (IV/8)

Altogether the training periods were found to be very good among most of the trainees. As mentioned earlier, teaching training is a very interactive process in which mentors (tutors), trainees and pupils are interacting. Class teachers (mentors) are always in charge of the class where a trainee is practicing. However, as the examples below show, the trainees also mentioned things that needed to be improved:

"Practice needed really a lot of work, and the days stretched nearly around the clock in planning the lessons. Group /personal guidance in different subjects were more effective if there were exact times when a teacher is present in order to give topics. Now a lot of extra time was spent "running after teachers" when I was trying to meet the teacher to get his or her topics. One could have used this time in planning the lessons. This happened again at the end of the practice period, when I needed the teacher's signature in my practicum card. I also found problematic the subjects in which there was only one lesson to teach. During one lesson there is not enough time to get acquainted with the topic and teaching is just touching the surface." (1/15)

"It seems that the training school does not have common rules of how the aims of training are mastered or how feedback is given to a trainee. For instance, while some teachers (mentors) want to have an hour-long feedback session every day, the others have them hardly ever. In TTP training one topic was the co-operation between home and school. Some, including yours truly, had to come to the parents evening and give a "presentation" about one's own training week, when the other trainees did not have this kind of obligation. Due to this the workloads differed greatly, and one cannot talk about equity...." (III/ 38)

"Students are not necessarily paid attention to. It would be polite to respect also trainees even if one is a class teacher. Also trainees have a very tight time schedule. Sometimes one has really to be resilient no matter how hungry and tired one is. Supervising teachers should also be flexible in some amount. 'I have to be then at coffee break'. I think this is an improper comment when we were trying to make an agreement of the time schedule. It should be left unsaid. The teachers get their salary, too. The supervising teacher sits at the end of the classroom, goes through his /her calendar and chews bubble gum mouth open. - A good example for us trainees. Sometimes it makes you wonder if the supervising teachers have got any training at all. How to give feedback? This is, however, the most important part of training." ( IV/7)

"I don't know how teachers are instructed to supervise, but at least my motivation to study dropped during this practice because all the feedback I got was negative. The substitute teacher was the only one from whom I got concrete hints for teaching and positive feedback. At the department, they always emphasize to use in feedback the so called hamburger model, both positive and critic. I understand that the meaning of practice is not to make a student to wonder one's own teacher hood or in general turning to the field, instead one should be encouraged and supported in building of one's teacher hood. I wish that also supervisors concentrated on this in the future." (IV/13)

The last examples include several good advises for supervisors. It is of great importance how the trainees are spoken to. All teacher educators, no matter in which role they act, should remember that they serve as role models for future teachers. Prospective teachers learn to interact and use different dialogue models during their education. One should not take it for granted that one is ready for supervising that instant one gets a position as a teacher educator. For this reason, it is also important to educate the supervisors. 


\section{Discussion}

In different teacher education departments in Finland, there are great differences in the amount of teaching practice. There has been long lasting debate of how much practice a teacher trainee should have. The truth is that no one can tell the quantity or the quality of training which would be optimal. The results of this study are similar to the results of Franke and Dahlgren (1996); the student teachers consider that the practical part of their education is the most important one. Another question that needs to be answered is; how much supervision or advice the mentors and tutors should give to trainees during the teaching practice. As the results of the study show, the trainees find the advice of the mentors to be more useful than the ones given by the tutors. In future, more attention should be paid to the role of a tutor in the teaching practice process. Nevertheless it is essential that tutors and mentors have the same goals concerning the training. Sometimes, as can be seen from the examples above, it is very confusing for a trainee to work in a classroom with different instructions given by the two parties.

The pivotal question is; what kind of roles a tutor (a university educator) and a mentor (a class teacher) take in the process of teaching practice? Do they give instructional support or psychological support to trainees (see Krull 2005) or are they preparing trainees for classroom management (see Clement 2010)? It is obvious that, as Jokinen and Välijärvi (2006) state "new teacher professionalism means more collegial collaboration, more sharing of different practices and more mutual support than before" (p.99).

Teacher education enhances all the time. When the new fall semester 2014 starts, the curriculum of the teacher education at the department of teacher education, Rauma unit, in the University of Turku, Finland, is already different than the one explained here, and hopefully it is also more effective. When planning the new curriculum, the aim was to keep in mind as well the feedback that had been received from the trainees as the statement by Järvinen, Kohonen, Niemi, and Ojanen (1995) "those involved in designing and putting into practice pre-service teacher education curricula need to be aware of the kinds of seeds they provide, both personally and as an institution" (p. 132).

We should also take in consideration the idea Le Cornu (2005) mentioned in her article: "There is a shift away from the mentor as expert, hierarchical one-way view to a more reciprocal relationship." (p. 356) She also refers to previous literature and terms such as co-mentoring, mutual mentoring, collaborative mentoring and critical constructivist mentoring which she says are reflecting the changes. Though Le Cornu is adapting this change to peer mentoring, we would like to see this change also among university tutors and mentors (see Figure 1). If cooperation between these two works well, it serves as a model for a student teacher, how people who might have different views to a topic can appreciate each other's views. This also needs open dialogue.

The interaction between the key triad members has been found to be complex (Valencia et al. 2009), but we should understand that it is a "collective" activity also involving many other actors than the key members of a triad: the pupils of those classes student teachers are teaching as well as other members of the school and the university community. This was also found in the answers of the trainees.

Although the results are not transferable to another teacher education, we found similarities with earlier studies, as we pointed out above. One of the major problems that emerged from the student teachers' answers was that most of the studies have concentrated on dyads; other important problems were related to the cooperation between tutors (university supervisors) and student teachers or mentors (cooperating teachers) and student teachers. It is obvious that more studies are needed about triads. Another interesting research question would be; how the gender affects the supervising process? Taylor (2008) argues that there are still very few studies done in the context of professional university programs like in the area of initial teacher education concerning learning of student teachers. As she states "these studies are important in that the findings are of consequence in the improvement of university teaching and student learning " (p. 68).

In teaching practice, mentors' role is to enhance trainees' professional skills, promote student-teachers' reflection on their practice, such as the lesson planning and lesson delivery as well as provide assistance and support. Altogether, their role is to facilitate prospective teachers' induction into the world of teaching and the school environment (Lai 2005/2006). The role of a mentor is more practical in comparison with the role of a tutor, which is a liaison between theory and practice. As Lai pointed out, mentoring can be seen taking place in a formal and informal manner. By the formal level of mentoring Lai means pre-lesson conferences, where a mentor and a trainee discuss about the planning of lessons and delivering them, the observations of a trainee's lessons, and post-lesson conferences where these two parties discuss the performance during the observed lessons. The informal level of mentoring is everything informal or unplanned supervision that takes place during the day. According to this definition, we could see the work of tutors to be more formal, since they observe the lessons of a trainee only some hours not being present the whole day. 
While reading the reflections of the students who attended to the four teaching practice periods, there was no clear evidence how the students processed their learning in teaching. During the first two periods, working with peer students and different subjects were in the center. One could say that the objectives for these two training periods were mastered, but students could not express exactly what they had learned, in most of the cases they only wrote what they had done during the training. There seemed to be so much to learn during the first basic practice that students could not see a pupil who came to the picture during the second basic training. The whole "picture" of teaching and a teacher's world opened for trainees during the third teaching practice period when they could teach a whole week. The fourth and last teaching practice strengthened and deepened their skills and knowledge in learning and assessment.

There is still much to be improved in teaching practice though the objectives of the training periods were mastered. The students should learn how to critically reflect their own practices (Harrison et. al. 2005) and social skills in teaching and learning situations. The co-operation between tutors, mentors and student teachers needs to be improve as well as the timing of the different training periods (among other things).

One can also question how reliable these answers were? Usually, when filling the questionnaire for the first time it is done properly, but already when doing it for the second time it seems to be for some students an obligatory task and this reaction could also be seen in the third and fourth time. One of the main questions to be negotiated in the near future is, for what reason is this kind of feedback data collected from the student teachers; is it only for the teacher education department, or for the training school, or is it for the students themselves, or to all these participants? What is the advantage of the feedback? It is obvious that more research on this field is needed, but which is the best form of collecting the data; is it a portfolio where students write their learning diaries, is it an interview, or is it an observation, or something else? The modern technology (see Grove, Strudler \& Odell 2004) provides new learning platforms, which should be used in teaching practice. In-service training for mentors and tutors should also be provided. Teacher educators should see the importance of these two roles, and not take it for granted that everyone who is appointed to be a mentor or tutor is right away qualified for supervising prospective teachers.

\section{References}

Bullough, Jr., R. V. \& Draper, R. J. (2004). Making Sense of a Failed Triad: Mentors, University Supervisors, and Positioning Theory. Journal of Teacher Education, 55(5), 407 - 420.

Clement, M. C. (2010). Preparing Teachers for Classroom Management: The Teacher Educator's Role. The Delta Kappa Gamma Bulletin, 77(1), 41 - 44.

Crasborn, F., Hennissen, P., Brouwer, N., Korthagen, F. \& Bergen, T. (2011). Exploring a two-dimensional model of mentor teacher roles in mentoring dialogues. Teaching and Teacher Education, . 27(2), 320 - 331.

Franke, A. \& Dahlgren L. O. (1996). Conceptions of Mentoring: An Empirical Study of Conceptions of Mentoring During the School-based Teacher Education. Teacher \& Teacher Education, 12(6), 627 - 641.

Grove, K., Strudler, N. \& Odell, S. (2004). Mentoring Toward Technology Use: Cooperating Teacher Practice in Supporting Student Teachers'. Journal of Research on Technology in Education 37(1), 85 - 109.

Harrison, J., Lawson, T. \& Wortley, A. (2005) Facilitating the Professional Learning of New Teachers through Critical Reflection on Practice during Mentoring Meetings. European Journal of Teacher Education, 28(3), 267 - 292.

Jakku-Sihvonen, R. \& Niemi, H. (2006). The Bologna Process and Its Implementation in Teacher Education, In R. JakkuSihvonen \& H. Niemi, (eds.) Research-based Teacher Education in Finland - Reflections by Finnish Teacher Educators (pp. 17 - 29) Research in Educational Sciences 25: Finnish Educational Research Association.

Jokinen, H. \& Välijärvi, J. (2006). Making Mentoring a Tool for Supporting Teachers' Professional Development, In R. JakkuSihvonen \& H. Niemi, (eds.) Research-based Teacher Education in Finland - Reflections by Finnish Teacher Educators (pp. 89 - 101) Research in Educational Sciences 25: Finnish Educational Research Association.

Jyrhämä, R. (2006). The Function of Practical Studies in Teacher Education, in R. Jakku-Sihvonen \& H. Niemi, eds. Research-based Teacher Education in Finland - Reflections by Finnish Teacher Educators (pp. 51 - 69) Research in Educational Sciences 25: Finnish Educational Research Association.

Järvinen, A., Kohonen, V., Niemi, H. \& Ojanen, S. (1995). Educating Critical Professionals. Scandinavian Journal of Educational Research, 39(2), $121-137$. 
Karavas, E. \& Drossou, M. (2009). A Comparative Investigation of Student Teacher and Mentor Beliefs During Teaching Practice, The International Journal of Learning, 16(7), 123-138.

Krull, E. (2005). Mentoring as a means for supporting student and beginning teachers' practice-based learning, TRAMES, 9(2), 143-158.

Lai, E. (2005/2006). In-Service Teachers' Perceptions of Teaching Practice Mentoring, International Journal of Learning, 12(6), 107-113.

Le Cornu, R. (2005). Peer mentoring: engaging pre-service teachers in mentoring one another. Mentoring and Tutoring, 13(3), $355-366$.

Levine, T. H. (2011). Features and strategies of supervisor professional community as a means of improving the supervision of preservice teachers. Teaching and Teacher Education, 27(5), 930 - 941.

Soininen, M. (2004). Tutors, Mentors and Student Teachers Working Together. Teacher as Researcher. Pictures and Perspectives of Teacher Professionalism, Journal of Teacher Researcher, 1, 117-127.

Taylor, A. (2008). Developing understanding about learning to teach in a university-schools partnership in England, British Educational Research Journal, 34(1), 63-90.

Valencia, S. W., Martin, S. D., Place, N. A. \& Grossman, P. (2009). Complex Interactions in Student Teaching. Lost Opportunities for Learning. Journal of Teacher Education, 60(3), $304-322$.

Veal, M. L. \& Rikard, L. (1998). Cooperating Teachers' Perspectives on the Student Teaching Triad. Journal of Teacher Education, 49(2), 108 - 119.

Zanting, A., Verloop, N. \& Vermunt, J. D. (2003). How do Student Teachers Elicit their Mentor Teachers' Practical Knowledge?, Teachers and Teaching: theory and practice, 9(3), 197-211.

Zanting, A., Verloop, N. \& Vermunt, J. D. (2001). Student Teachers' Beliefs about Mentoring and Learning to Teach during Teaching Practice, British Journal of Educational Psychology, 71, 57-80. 